\title{
Field evaluation of the application of time temperature integrators for monitoring food quality in the cold chain
}

\author{
Petros S. Taoukis \\ Laboratory of Food Chemistry and Technology, School of Chemical Engineering, \\ National Technical University of Athens, Greece, taoukis@chemeng.ntua.gr
}

\begin{abstract}
Monitoring of temperature conditions of chilled products is crucial for safety, quality and shelf life management. A cost-effective way is the application of suitable Time Temperature Integrators (TTI), small, inexpensive devices that show an easily measurable, time-temperature dependent change that reflects the temperature history of the food products. Since the rate of change depends on temperature, TTI response offers an integrated representation of the storage conditions. Prerequisite for application of TTI is the development of a correlation scheme, which would translate TTI response to the quality status of the food at any point of the distribution chain. Basic structural elements of this scheme are validated kinetic models of TTI response and kinetics of the degradation indices of the food, such as predictive models of microbial growth. A novel chill chain management system, coded SMAS, uses the information from the TTI response at designated points of the chill chain, ensuring that the temperatureburdened products reach consumption at acceptable quality level. The effectiveness of the TTI based SMAS system was evaluated by running a large number of chill chain scenarios using a Monte Carlo simulation approach. Field test experiments to demonstrate and quantify the improvement at the time of consumption in comparison to the conventional First In First Out (FIFO) rule, were also conducted. These experiments involved microbiological measurements of all products at "consumption time". The spoilage profile with the SMAS approach was significantly improved in all experiments demonstrating the usefulness of TTI monitoring and the applicability of SMAS for managing the chill chain.
\end{abstract}

Key words : Time temperature integrators, TTI, shelf life modelling, chill chain, food kinetics, FIFO, Arrhenius, smart labels, temperature monitoring

\section{Introduction}

In the real food chain, deviations from the specified temperature conditions of chilled or frozen distribution are very often encountered (Taoukis et al., 1998; Giannakourou and Taoukis, 2003). Temperature is the main shelf life determining post-processing parameter for chilled and frozen products and therefore monitoring it is an essential prerequisite for effective shelf life management. The complexity of such a task can be realized when the variation in temperature exposure of single products within batches or transportation subunits is taken into account. A cost-efficient way to individually monitor the temperature history of food products throughout distribution would be required in order to indicate their real quality level. Time-Temperature Integrators (TTI) can effectively fulfil this task (Taoukis and Labuza, 2003). Based on reliable models of food product shelf life and the kinetics of TTI response the effect of temperature can be monitored, recorded and translated, from production to the consumer's table. A TTI based system could lead to realistic control of the 
chill chain, optimization of stock rotation and reduction of waste, and efficient shelf life management.

A novel chill chain management system, coded SMAS, was developed (Koutsoumanis et al., 2005) in order to use the information from the TTI response at designated points of the chill chain, ensuring that the temperature-burdened products reach consumption at acceptable quality level. The effectiveness of the TTI based SMAS system was evaluated by simulations and field test experiments in order to demonstrate and quantify the improvement in food product quality at the time of consumption in comparison to the conventional First In First Out (FIFO) rule.

\section{Time Temperature Integrators}

TTI are inexpensive, active "smart labels" that can show an easily measurable, timetemperature dependent change that reflects the full or partial temperature history of a food product to which it is attached (Taoukis and Labuza,1989). The principle of TTI operation is a mechanical, chemical, enzymatic or microbiological irreversible change usually expressed as a visible response, in the form of a mechanical deformation, colour development or colour movement. The rate of change is temperature dependent, increasing at higher temperatures similarly to the deteriorative reactions responsible for the food spoilage. The visible response of the TTI thus cumulatively reflects the time-temperature history of the food product it accompanies.

A number of TTI systems have been proposed in the past of which few reached the industrial prototype and fewer achieved commercial application. TTI that are currently available and target to satisfy most of the above requirements are based on different operation principles.

The CheckPoint ${ }^{\circledR}$ TTI, (VITSAB A.B., Malmö, Sweden) is an enzymatic system. The TTI is based on a color change caused by a $\mathrm{pH}$ decrease which is the result of a controlled enzymatic hydrolysis of a lipid substrate. Hydrolysis of the substrate causes acid release and the $\mathrm{pH}$ drop is translated in a color change of a $\mathrm{pH}$ indicator from deep green to bright yellow to orange red Different combinations of enzyme-substrate types and concentrations can be used to give a variety of response lives and temperature dependencies.

The Fresh-Check ${ }^{\circledR}$ TTI (Temptime Corp., Morris Plains, NJ, USA) are based on a solid state polymerization reaction, resulting in a highly coloured polymer. The response of the TTI is the color change measurable as a decrease in reflectance. The colour of the 'active' centre of the TTI is compared to the reference color of a surrounding ring. Before use the indicators, active from the time of production, have to be stored deep frozen where change is very slow. The $\mathrm{OnVu}^{\mathrm{TM}}$ TTI (Ciba Specialty Chemicals \& Freshpoint, SW) is a newly introduced solid state reaction TTI. It is based on the inherent reproducibility of reactions in crystal phase. Photosensitive compounds are excited and coloured by exposure to low wavelength light. This colored state reverses to the initial colorless at a temperature depended rate. This TTI can take the form and applied as a photosensitive ink.

The (eO) ${ }^{\circledR}$ TTI (CRYOLOG, Gentilly, France) is based on a time-temperature depended $\mathrm{pH}$ change caused by controlled microbial growth that is expressed to colour change through suitable $\mathrm{pH}$ indicators.

The TT Sensor ${ }^{\text {TM }}$ TTI (Avery Dennison Corp., USA) is based on a diffusion-reaction concept that causes the color change of the indicator from yellow to bright pink.

The 3M Monitor Mark ${ }^{\circledR}$ (3M Co., St. Paul, Minnesota) is based on diffusion of proprietary polymer materials. A viscoelastic material migrates into a diffusely light-reflective porous matrix at a temperature dependent rate. The response rate and temperature dependence is controlled by the tag configuration, the diffusing polymer's concentration and its glass transition temperature and can be set at the desirable range. 
Use of TTI can help optimize food distribution, improve shelf life monitoring and management and thus reduce food waste and benefit the consumer improving shelf life monitoring and management. Cost, reliability, and effective application are criteria for practical success of TTI. The cost is volume dependent, ranging from 2 to 20 cents per unit. Current TTI systems provide reliable and reproducible responses according to their specifications. With regards effective application of the suitable TTI for the intended food product, it has been widely assumed that the response of the TTI should exactly mimic quality deterioration behavior of the food to be monitored at all temperatures. This approach would require an unlimited number of TTI models. Instead, a methodology of translating TTI response to food status based on systematic modeling of both the TTI and the food could be used as a tool for food quality monitoring and shelf life management.

Determination and modeling of the shelf life or keeping quality of the food products is the most important prerequisite for the application of a TTI based monitoring and management system, usually evaluated by the measurement of the change of one or more characteristic quality indices, A, with time $\mathrm{t}$, and expressed as

$$
\mathrm{f}(\mathrm{A})=\mathrm{k}(\mathrm{T}) \mathrm{t}
$$

where $\mathrm{f}(\mathrm{A})$ is the quality function of the food and $\mathrm{k}$ the reaction rate constant.

The rate constant is an exponential function of inverse absolute temperature, $\mathrm{T}$, given by the Arrhenius expression,

$$
\mathrm{k}=\mathrm{k}_{\text {ref }} \exp \left[\frac{-\mathrm{E}_{\mathrm{A}}}{\mathrm{R}}\left(\frac{1}{\mathrm{~T}}-\frac{1}{\mathrm{~T}_{\text {ref }}}\right)\right]
$$

where $\mathrm{k}_{\mathrm{ref}}$ is the reaction rate constant at a reference temperature $\mathrm{T}_{\mathrm{ref}}, \mathrm{E}_{\mathrm{A}}$ is the activation energy of the reaction that controls quality loss and $\mathrm{R}$ the universal gas constant. The form of the quality function of the food depends on the reaction order of the phenomenon controlling the deterioration of the food e.g. $f(A)=\ln \left(A_{o} / A_{t}\right)$ for $n=1$ order and $f(A)=\left[A_{t}^{1-n}-A_{o}^{1-n}\right] / n-1$ for $n \neq 1$. The activation energy of food related chemical reactions and spoilage or pathogenic microbial growth usually falls within $30-140 \mathrm{~kJ} / \mathrm{mol}$ (Taoukis et al., 1997).

The value of the quality function, $f(A)_{t}$, at time $t$, after exposure of the food at a known variable temperature exposure, $\mathrm{T}(\mathrm{t})$, can be found based on equation (1) by calculating the integral of $k[\mathrm{~T}(\mathrm{t})] \mathrm{dt}$, from 0 to time $\mathrm{t}$. We can define the effective temperature, $\mathrm{T}_{\text {eff, }}$ as the constant temperature exposure to which for the same time results in the same quality value, $\mathrm{f}(\mathrm{A}) \mathrm{t}$, as the variable temperature distribution, $\mathrm{T}(\mathrm{t})$. The same kinetic approach can be used to model the measurable change $\mathrm{X}$ of the TTI. If a response function $\mathrm{F}(\mathrm{X})$ can be defined such that $\mathrm{F}(\mathrm{X})=\mathrm{kt}$, with $\mathrm{k}$ an Arrhenius function of $\mathrm{T}$, then the effective temperature concept as described above can also be used for the TTI. For an indicator exposed to the same temperature distribution, $\mathrm{T}(\mathrm{t})$, as the food product, and corresponding to an effective temperature $\mathrm{T}_{\text {eff }}$, the response function can be expressed as

$$
\mathrm{F}(\mathrm{X})_{\mathrm{t}}=\mathrm{k}_{\mathrm{I}_{\text {ref }}} \exp \left[\frac{-\mathrm{E}_{\mathrm{A}_{\mathrm{I}}}}{\mathrm{R}}\left(\frac{1}{\mathrm{~T}_{\text {eff(TTI) }}}-\frac{1}{\mathrm{~T}_{\text {ref }}}\right)\right] \mathrm{t}
$$

where $\mathrm{k}_{\mathrm{I}_{\mathrm{ref}}}$ and $\mathrm{E}_{\mathrm{AI}}$ are the Arrhenius parameters of the indicator.

Thus for applying a TTI based food quality monitoring scheme we need to experimentally define the quality function of the food, the response function of the TTI and the respective kinetic parameters. From the measured response X of the TTI at time the value of the response function is calculated, from which by solving equation (3), the $\mathrm{T}_{\text {eff }}$ of the exposure is derived. With the $T_{\text {eff }}$ and the kinetic parameters of the food known, the quality function 
value is calculated from equations (2) and (1), and the value of index A is found. This gives the extent of the quality deterioration of the food and allows the calculation of the remaining shelf life at any reference conditions.

The developed principles give a potential user the ability to select and apply the most appropriate TTI without the need of extensive side by side testing of the product and the TTI. A TTI with an activation energy $E_{\mathrm{AI}}$ that differs from the food's $\mathrm{E}_{\mathrm{A}}$ by less than $20 \mathrm{~kJ} / \mathrm{mol}$ would result in a $\mathrm{T}_{\text {eff }}$ estimation of the food within $\pm 1^{\circ} \mathrm{C}$.

The information provided by the TTI, translated to remaining shelf life at any point of the chill chain can be used to manage shelf life by improving distribution control and a stock rotation practices. The approach currently used is the First In First Out (FIFO) system according to which, products received first and/or with the closest expiration date on the label are shipped, displayed and sold first. This approach aims in establishing a "steady state" with all products being sold at the same quality level. The assumption is that all products have gone through uniform handling, thus quality is basically a function of time. The use of the indicators can help establish a system that does not depend on this unrealistic assumption. The objective is again a "steady state" situation with the least remaining shelf life products being sold first. This approach was coded LSFO (Least Shelf-life First Out). The LSFO reduces the number of rejected products and largely eliminates consumer dissatisfaction since the fraction of product with unacceptable quality at consumption is minimized. LSFO aims at reducing the rejected products at the consumer end, by promoting, at selected decision making points of the product life cycle, those product units with the shorter shelf life, according to the response of the attached TTI (Taoukis et al., 1998; Giannakourou and Taoukis, 2002). The above elements form the core of an integrated software that allows the calculation of the actual remaining shelf life of individual product units at strategic control points of the chill chain (Figure 8). Based on the distribution of the remaining shelf life, decisions can be made for optimal handling, shipping destination and stock rotation, aimed at obtaining a narrow distribution of quality at the point of consumption. A further improvement of the LSFO approach, is a chill chain management system coded SLDS (ShelfLife Decision System (Giannakourou et al., 2003). Compared to LSFO, SLDS policy takes additionally into account the realistic variability of the initial quality state $\mathrm{A}_{\mathrm{o}}$ of the product. The state of the TTI technology and of the scientific approach with regards the quantitative safety risk assessment in foods allows the undertaking of the next important step i.e. the study and development of a TTI based management system that will assure both safety and quality in the food chill chain (Koutsoumanis et al., 2005). The development and application of such a system coded with the acronym SMAS was the target of the multinational European research project "Development and Modeling of a TTI based Safety Monitoring and Assurance System (SMAS) for chilled Meat Products" (project QLK1-CT2002-02545, 20032006; http://smas.chemeng.ntua.gr).

The objective of this work was to experimentally demonstrate the effectiveness of the TTI based SMAS system and quantify the improvement at the time of consumption in comparison to the conventional FIFO approach.

\section{Materials and Methods}

CHILL CHAIN SIMULATION : In order to test the potential use of TTI in monitoring the shelf life of fresh pork cuts, the following experiment was designed. 120 products of fresh pork cuts, MA packed $\left(60 \% \mathrm{CO}_{2}\right)$, were used . On half, 2 enzymatic TTIs (TTI-M4-6 and TTI-L4-11 Check Point ${ }^{\circledR}$, Vitsab, Sweden) were attached and activated on packing time. All products entered the regular transportation route to the main distribution center and then were stored in programmable cabinets simulating the conditions of the real chill chain to the point 
of consumption. The simulated chill chain conditions consisted of 6 different timetemperature scenarios that were conducted in controlled temperature cabinets (Sanyo MIR 153, Sanyo Electric Co, Ora-Gun, Gunma, Japan) and they are illustrated in Figure 1.

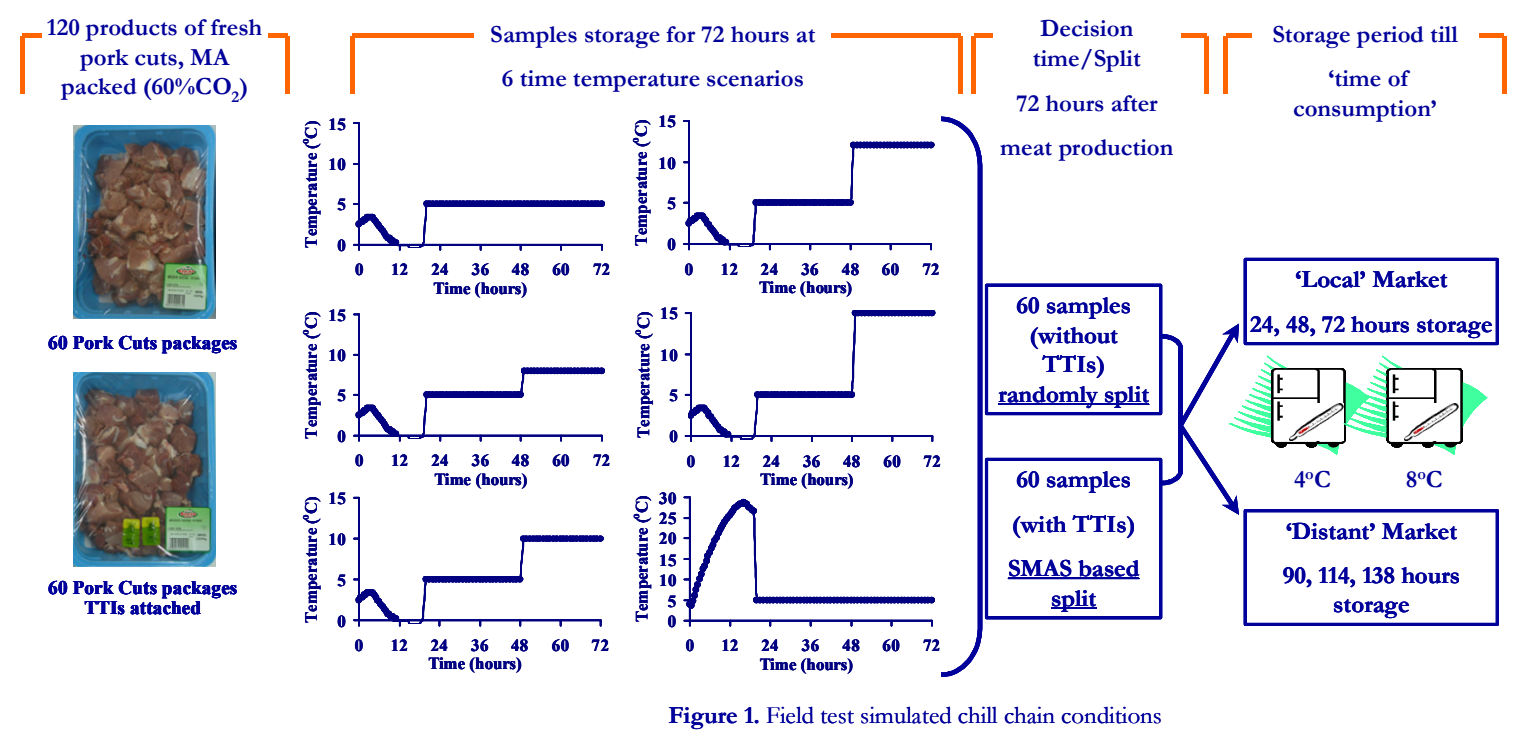

Figure 1. Field test - simulated chill chain conditions

The Check Point ${ }^{\circledR}$ TTI starts from initial green colour, becomes progressively yellow, orange and reaches a final orange-red color (Fig. 2).

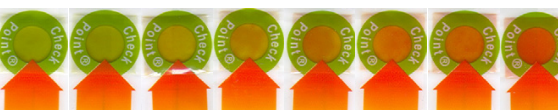 \\ 1020304050607080}

Figure 2. The 8-stage color reference scale for the Check Point ${ }^{\mathbb{B}}$ indicators .

The M4-6 TTI was designed to expire within 6 days at $4{ }^{\circ} \mathrm{C}\left(\mathrm{E}_{\mathrm{A}}=21 \mathrm{kcal} / \mathrm{mol}\right)$ and L4-11 TTI having a higher activation energy $\left(\mathrm{E}_{\mathrm{A}}=48 \mathrm{kcal} / \mathrm{mol}\right)$, and being more temperature sensitive, expire in 2 days at $10^{\circ} \mathrm{C}$ (Fig. 3).

Color change readings of the attached TTIs were taken throughout the field test at appropriate time corresponding to critical stage of the actual transportation process (e.g. distribution center) at a designated decision time, 72 hours after meat product packaging. TTI visual reading was conducted with an 8-point TTI color reference scale, constructed from TTIs inactivated at a certain level (Figure 3). 


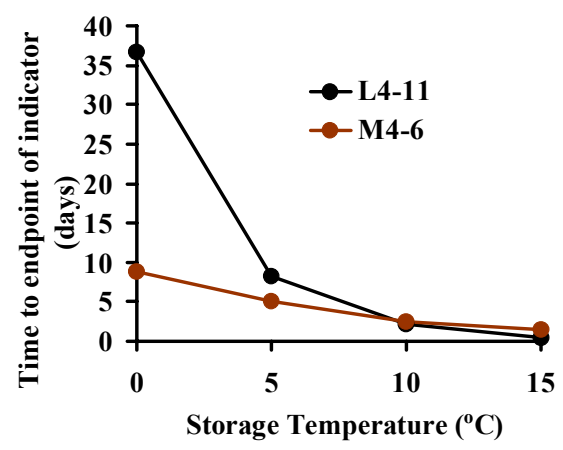

Figure 3. Response time of M4-6 \& L4-11

TTI at the temperature range of $0-15^{\circ} \mathrm{C}$.

DECISION TIME - SMAS APPLICATION -SPOILAGE MEASUREMENT : 72 hours after meat product packaging (at which products leave the central distribution center) the samples were split in half and promoted to two different destinations with different transport duration, a distant and a local one. SMAS handled products' split was based on TTI response (color stage) translated into temperature history based on TTI kinetics. According to the SMAS concept, the more temperature burdened products were diverted to the 'local' market shortening their life cycle in order to be consumed first. The 60 meat products handled with the FIFO (First In First Out) approach were split randomly. After split all 120 samples were stored at 2 storage cabinets at $4^{\circ} \mathrm{C}$ and $8^{\circ} \mathrm{C}$ for different times simulating the different final consumption times of products sold at the local and the distant market (Figure 1)

Microbiological analyses of the respective meat products were conducted at the 6 different stages. Products that were sold at the 'local' market were microbiologically analyzed at 24, 48 and 72 hours after the split. Products sold at the 'distant' market were microbiologically analyzed 90, 114 and 138 hours after the split. Lactic acid bacteria level, identified as the specific spoilage organism of MA packed pork cuts, was measured at the end of storage period (assumed as time of consumption).

\section{Results and Discussion}

SMAS system and FIFO approach were applied on fresh, MA packed $\left(60 \% \mathrm{CO}_{2}\right)$ pork cuts. The effectiveness of the SMAS system was evaluated based on the level of Lactic acid bacteria at the end of storage. Samples with Lactic acid bacteria level above $10^{7} \mathrm{cfu} / \mathrm{g}$ (spoilage level) were characterized as spoiled. The initial level of Lactic acid bacteria was 3.2 $\log \mathrm{cfu} / \mathrm{g}$. In figures $4 \mathrm{a}$ and $4 \mathrm{~b}$ the distributions of Lactic acid bacteria level for the 'local' and 'distant' market samples are illustrated. With FIFO approach 13 out of 60 samples 'local' and 'distant' promoted- (21.6\%) reached the spoilage level at the end of storage period. When the SMAS based sorting is applied, 6 out of 60 samples $(10 \%)$ reached the spoilage level, significantly reducing the number of spoiled products before the 'time of consumption'. 


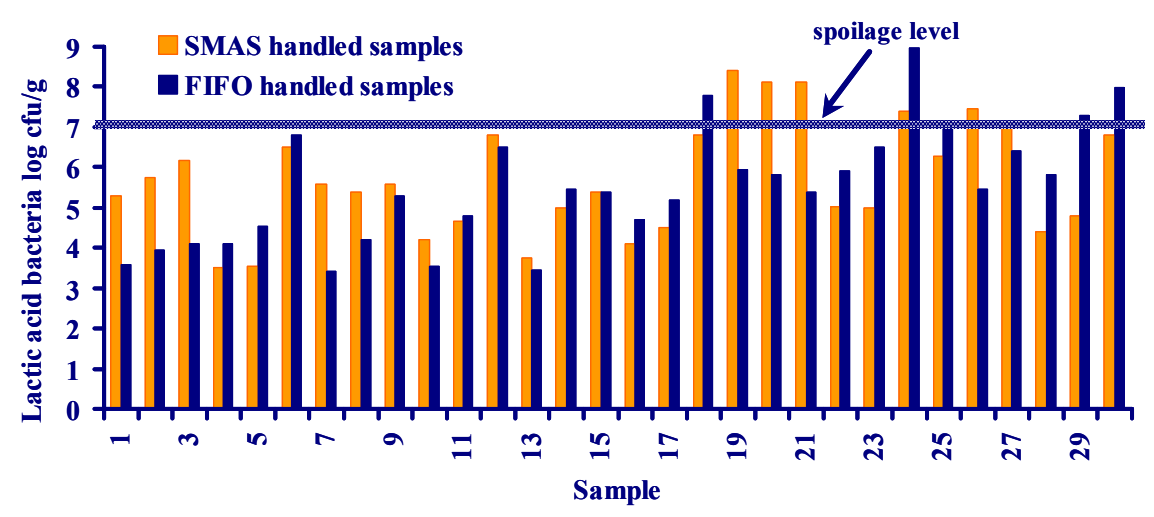

(a)

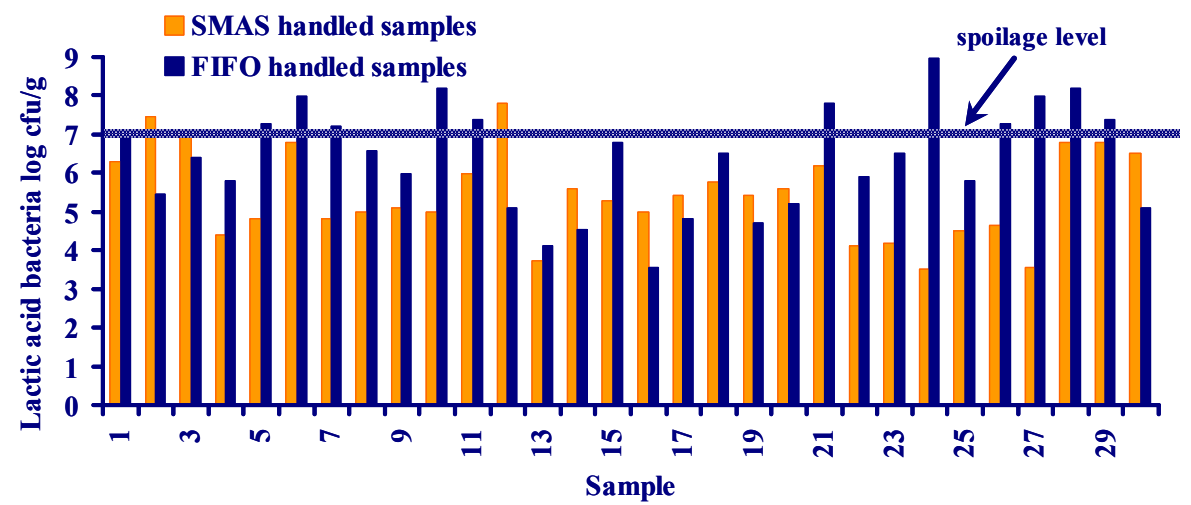

(b)

Figure 4. Measured lactic acid bacteria log counts in pork cuts samples promoted to (a) the 'local' and (b) the 'distant' market based on FIFO and SMAS approach.

In Figure 5 the distribution of the remaining shelf life of pork cuts at the 'time of consumption' is depicted. In total (for both 'local' and 'distant' market) SMAS system resulted in reducing the number of spoiled products. These results were confirmed with extensive theoretical calculations using Monte Carlo simulation for thousands of scenarios based on predictive models for microbial growth and a large database of temperature distributions obtained from studies throughout the chill chain. With the same approach it was demonstrated that the distribution of risk from incidental meat pathogens (assumed initial low contamination with Listeria monocytogenes), was also significantly reduced (Fig.6).

\section{Conclusion}

SMAS uses the information from the TTI, at appropriate points of the chill chain (e.g at a central distribution center), to make decisions for the further management of products based on their temperature history and hence microbial status. The conducted field test demonstrates the applicability of the TTI based SMAS approach to improve the meat chill chain. The overall field test result showed that the SMAS based sorting at a decision point resulted in substantially reducing the spoiled products at the time of consumption in comparison with the conventional FIFO approach. 


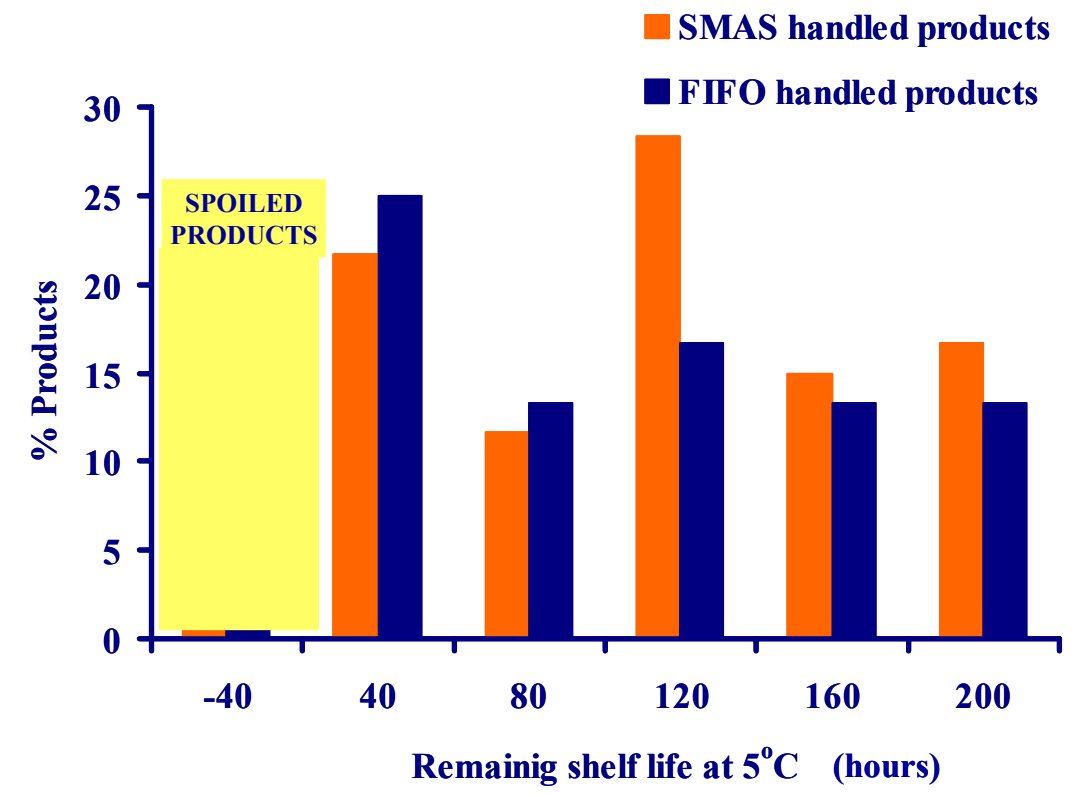

Figure 5. Distribution of the remaining shelf life of pork cuts at the time of 'consumption' with FIFO and SMAS approach.

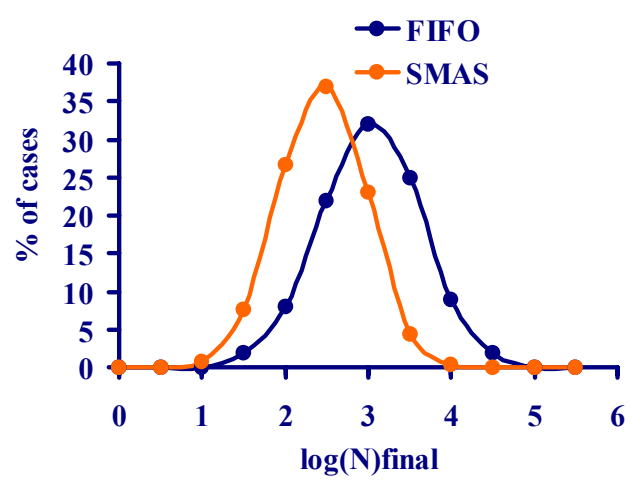

(a)

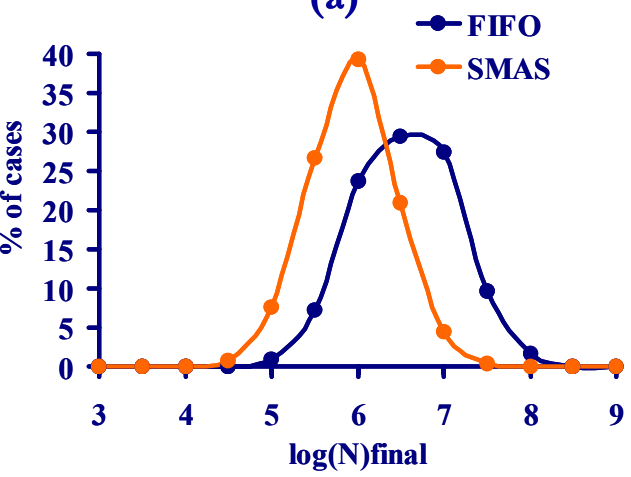

(c)

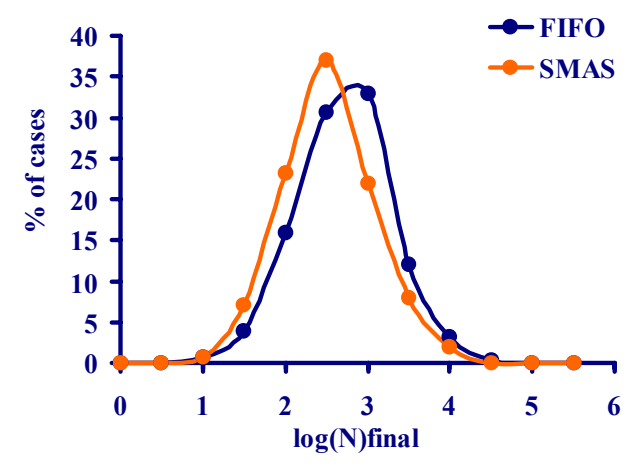

(b) $\rightarrow$-FIFO

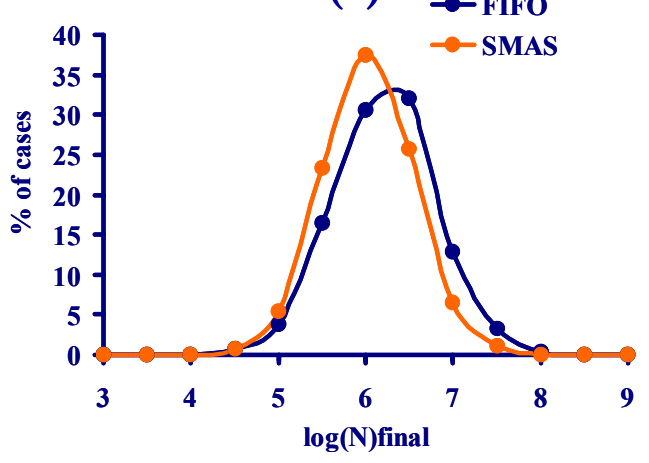

(d)

Figure 6. Monte Carlo simulation output. Distribution of Listeria Monocytogenes growth for products promoted to (a) the export, (b) local market and distribution of Lactic acid bacteria growth for products promoted to (c) the export and (d) local market. 


\section{Acknowledgement}

This study has been partly carried out with the financial support of the Commission of the European Communities, specific RTD program "Quality of Life and Management of Living Resources", Key Action 1-Health Food and Environment, Project N QLK1-CT2002-02545 (http://smas.chemeng.ntua.gr).

\section{References}

Giannakourou M.C., Koutsoumanis K., Nychas G.J.E., Taoukis P.S. 2001. Development and assessment of an intelligent shelf life decision system for quality optimisation of the food chill chain. J Food Prot. 64(7), 1051-1057.

Giannakourou M.C., Taoukis P.S. 2002. Systematic application of Time Temperature Integrators as tools for control of frozen vegetable quality. J.Food Sci. 67(6): 2221-2228.

Giannakourou M.C., Taoukis, P.S. 2003. Application of a TTI-based distribution management system for quality optimisation of frozen vegetables at the consumer end. J.Food Sci. , 68(1): 201-209.

Koutsoumanis K, Taoukis PS, Nychas GJE. 2005. Development of a Safety Monitoring and Assurance System (SMAS) for chilled food products. Int. J. Food Micro., 100: 253-260.

Taoukis P.S., Bili M., Giannakourou M. 1998. Application of shelf life modeling of chilled salad products to a TTI based distribution and stock rotation system. In: Proceedings of the International Symposium on Applications of modeling as an innovative technology in the Agri-food chain. Tijkens LMM, Hertog MLATM. eds. Acta Horticulturae, 476:131-140.

Taoukis P.S., Labuza T.P. 1989 Applicability of Time Temperature Indicators as shelf life monitors of food products, J. Food Sci., 54, 783-788.

Taoukis PS. and Labuza T.P. 2003. Time-Temperature Indicators (TTI). In: Novel Food Packaging Techniques. R. Ahvenainen, ed. Woodhead Publishing Limited, Cambridge, UK and CRC Press LLC, Boca Raton FL, USA, 103-126

Taoukis, P., Labuza, T. P. and Saguy, I. 1997. Kinetics of Food Deterioration and Shelf-Life prediction. In: The Handbook Of Food Engineering Practice, K.J. Valentas, E. Rotstein, R. P. Singh eds., CRC Press, Boca Raton FL, USA, 1997; 361-403. 